\title{
Campaign Finance Laws and Political Efficacy: Evidence From the States*
}

\author{
David M. Primo ${ }^{\dagger}$ \\ University of Rochester \\ Jeffrey Milyo \\ University of Missouri
}

This Version: June 2005

\begin{abstract}
The decline of political efficacy and trust in the United States is often linked to the rise of money in politics. Both the courts and reform advocates justify restrictions on campaign donations and spending as necessary for the improvement of links between the government and the governed. We conduct the first test of whether campaign finance laws actually influence how citizens view their government by exploiting the variation in campaign finance regulations both across and within states during the last half of the 20th century. Our analysis reveals no large positive effects of campaign finance laws on political efficacy. Public disclosure laws and limits on contributions from organizations are in some cases associated with modest increases in efficacy, but public financing is associated with a similarly modest decrease in efficacy.
\end{abstract}

*Previous versions of this paper were presented at the 2003 Annual Meeting of the American Political Science Association and 2003 Annual Meeting of the Midwest Political Science Association. We thank Barry Burden, Dick Niemi, the editors, and anonymous reviewers for helpful comments. Thanks also to Matt Jacobsmeier and Matt Stiffler for research assistance.

${ }^{\dagger}$ Department of Political Science, University of Rochester, Harkness Hall, Rochester, NY 146270146; 585-273-4779; david.primo@rochester.edu; Fax: 585-271-1616

${ }^{\ddagger}$ Department of Economics and Truman School of Public Affairs, University of Missouri, 118 Professional Building, Columbia, MO 65211; 573-882-5572; milyoj@missouri.edu; Fax: 573-882-2697 


\section{Introduction}

A failure to regulate the arena of campaign finance allows the influence of wealthy individuals and corporations to drown out the voices of individual citizens ... causing the public to become disillusioned with and mistrustful of the political system.

-U.S. Ninth Circuit Court of Appeals, Jacobus v. State of Alaska, 2003

Do campaign finance regulations affect how citizens view their government? This question is both theoretically important and policy-relevant. A central argument for more restrictive campaign finance laws at both the state and federal levels is that tighter rules will restore trust in the government and make citizens once again feel that they can affect the political process. Supreme Court decisions upholding the constitutionality of campaign finance regulations acknowledge that the maintenance of confidence in government can sometimes override free-speech concerns. Yet the purported link between campaign finance law and perceptions of government has never been established systematically. In fact, there is good reason to doubt the existence of such a link, as both Primo (2002) and Coleman and Manna (2000) argue that there is little or no relationship between total campaign spending in federal elections and average trust in government at the national level. In fact, Freedman, Franz, and Goldstein (2004) find that campaign advertising (and, therefore, campaign spending) increases interest levels, knowledge, and turnout, suggesting that spending may in fact be a net positive for democracy. ${ }^{1}$

Given the central role that trust and efficacy play in scholarly and policy discussions about campaign finance reform, it is surprising that no study has directly examined the connection between existing campaign finance laws and how citizens view their government. ${ }^{2}$ Nevertheless, institutional reforms are widely thought to be

\footnotetext{
${ }^{1}$ This point is also made by Coleman and Manna (2000).

${ }^{2}$ One reason for the dearth of such evidence is that until recently, most rigorous academic work on campaign finance has been limited to attempts at measuring the effect of either campaign spending on electoral outcomes or campaign contributions on policy outcomes. (On the effects of campaign spending and electoral outcomes, see especially Levitt 1994 and Gerber 1998; on the effects of campaign contributions on roll-call votes, see especially Stratmann 1998, Bronars and Lott 1998,
} 
a potential policy lever for strengthening democracy. For example, Hibbing and Theiss-Morse (1995) discuss possible reforms within Congress that might increase public support for the institution. These include term limits (which have since been ruled unconstitutional for Congressional offices), a balanced budget rule, and what the authors term "serious" campaign finance legislation (Hibbing and Theiss-Morse 1995, 62-83). Weber argues that if several state-level reforms are implemented, including the creation of independent commissions to oversee campaign finance in the states, then "the result will be a restoration of public confidence in state legislatures" (Weber 1999, 625-626). Goidel, Gross, and Shields (1999, 12) also argue that campaign finance reforms will "improve the quality of American democracy," though none of these authors explicitly test the hypothesis that campaign finance laws are related to political efficacy. ${ }^{3}$ Despite these positives, Gross and Goidel claim (but do not demonstrate) that reform may also have a negative side:

... the consideration of reform temporarily appeased an increasingly cynical and alienated public while feeding the media establishment with sound bites on the evils of money. But, in the long run, it undoubtedly increased public cynicism and added to public alienation, even as it protected individual members of Congress who could claim to be in favor of reform without ever having to abide by its provisions (Gross and Goidel 2003, ix, emphasis added).

A few studies have attempted to empirically connect campaign finance and views on government. Grant and Rudolph (2004) adopt an experimental approach to study the foundations of public support for campaign finance reform, especially the tension between the values of liberty and equality. Persily and Lammie (2004) use descriptive data and indirect tests to establish that the likely link between federal campaign finance law and trust in government is weak. Like Primo (2002),

and Levitt 1998.) In addition, these efforts focus on the federal level; since federal campaign finance laws have been relatively stable over the past two decades, there has been little opportunity for systematic analysis regarding the impact of these laws.

${ }^{3} \mathrm{~A}$ recent review of the literature on money in American politics and its lessons for policy does not address whether campaign finance laws influence political efficacy or trust, underscoring the lack of evidence on this question (Mann 2003). 
they point out that campaign finance law is unique in jurisprudence because public opinion is deemed directly relevant for determining whether or not a law is constitutional. The authors go on to note that the evidence brought to bear in court cases tends to be of two forms: (1) anecdotal (e.g., news accounts) or (2) data showing that the public is distrustful of government and would like to see more campaign finance reform. ${ }^{4}$ What is missing, as we show below, is evidence that reform will lead to improved trust in government.

Two recent studies (Goidel, Gross, and Shields 1999; Coleman and Manna 2000) examine a related issue: the relationship between spending in U.S. House elections and individual survey responses to NES questions on efficacy or knowledge. These authors reach nearly opposite conclusions, with Coleman and Manna finding some evidence that campaign spending may improve knowledge and efficacy, and Goidel et al. finding some evidence to the contrary. These disparate findings may be attributable to the different methodological approaches taken by the authors. For example, Goidel et al. do not examine the potential endogeneity of campaign spending and efficacy or knowledge, while Coleman and Manna instrument for spending. 5

The public debate over state and federal campaign finance reform has likewise generated frequent and unsupported assertions that such reforms will restore faith in democracy. For example, Common Cause president Don Simon, commenting on the 2002 Bipartisan Campaign Reform Act (BCRA), stated, "I think it makes a huge difference that the world of soft money has come to an end. The law took a half a billion dollars off the political table, and it makes a whole lot of difference in the way the process works, and for the confidence the American people have in the system" (Vlahos 2003). But perhaps no example is as telling as when Senator John

\footnotetext{
${ }^{4}$ There is reason to think that news accounts, by focusing on extreme examples of spending or corruption, may in fact be part of the problem. See Ansolabehere, Snowberg, and Snyder (2005).

${ }^{5}$ As often occurs when instrumenting in political science, Coleman and Manna's instruments, which include incumbent and challenger quality and lagged vote share, may themselves be endogenous (either because of simultaneity or because of correlation with unobserved omitted variables).
} 
McCain (R-AZ) took to the Senate floor to argue in support of reform:

The Senator from Kentucky [Mitch McConnell] said the other day that there is no evidence, no polling data, no indication at all that the people's estrangement from Congress would be repaired by campaign finance reform. He is correct, there is no such evidence (Congressional Record 1999).

McCain then went on to explain that he had a "hunch" that reform would improve citizens' views of the Congress. But if there is no evidence that campaign finance reforms improve trust and political efficacy, why do proponents of reform frame their arguments in this manner? The answer is found in the rationale provided by the Supreme Court for permitting restrictions that otherwise infringe on First Amendment freedoms.

In the landmark Buckley v. Valeo (424 U.S. 1, 1976) decision in 1976, the Court specifically refers to confidence in government and the dangers unchecked campaign contributions pose for representative government:

Of almost equal concern as the danger of actual quid pro quo arrangements is the impact of the appearance of corruption stemming from public awareness of the opportunities for abuse inherent in a regime of large individual financial contributions. In CSC v. Letter Carriers [413 U.S. 548, 1973] ... the Court found that the danger to 'fair and effective government' posed by partisan political conduct on the part of federal employees charged with administering the law was a sufficiently important concern to justify broad restrictions on the employees' right of partisan political association. Here, as there, Congress could legitimately conclude that the avoidance of the appearance of improper influence 'is also critical . . . if confidence in the system of representative Government is not to be eroded to a disastrous extent.'

This line of reasoning is reiterated in Nixon v. Shrink Missouri Government PAC (528 U.S. 377, 2000), although the majority opinion also explicitly notes the absence of evidence that campaign finance laws influence public trust in government. ${ }^{6}$ The

\footnotetext{
${ }^{6}$ Writing for the majority, Justice Souter argues: "The state statute is not void, however, for want of evidence."
} 
Ninth Circuit Court of Appeals has also referenced the presumed connection between campaign finance reform and trust in government (see the epigraph on page one).

Most recently, in McConnell v. FEC (540 U.S. 93, 2003), the Supreme Court repeatedly appeals, often in reference to past decisions, to the "eroding of public confidence in the electoral process through the appearance of corruption" (pp. 3 and 26) as a justification for limits on large contributions to political parties. Limiting the appearance of corruption is also deemed to be of "almost equal' importance" (p. 34) as limiting actual corruption for preserving the "integrity of democratic process" (p. 26). Interestingly, while the Court cites "common sense" (p. 35) and several anecdotes regarding contributions and access to policy makers as support for the claim that campaign finance is critically linked to political efficacy and trust in government, no evidence is cited regarding actual (i.e., criminal) corruption, nor is there any evidence cited regarding the presumed pernicious impact of campaign contributions on public opinion. ${ }^{7}$ Overall, the Court does not offer any evidence that legal reforms influence public opinion about the integrity of the democratic process, perhaps because the link is taken to be self-evident. ${ }^{8}$ Justice Stephen Breyer, in a series of lectures at Harvard University, commented, "[Campaign finance laws] seek to democratize the influence that money can bring to bear on the electoral process, thereby building public confidence in the process..." (2004).

Our discussion thus far establishes two facts: 1) policy makers, scholars, and judges assert that campaign finance reform will improve popular perceptions of the democratic process, and 2) there is no systematic evidence that directly supports or contradicts this claim. In what follows, we address this disconnect by conducting the first test of the effect of campaign finance reforms on political efficacy. In

\footnotetext{
${ }^{7}$ Page numbers here refer to the slip opinion, available on the Supreme Court website, http://www.supremecourtus.gov/opinions/03slipopinion.html.

${ }^{8}$ See Persily and Lammie (2004) for further discussion of how the courts view the appearance of corruption rationale justifying campaign finance reform.
} 
particular, we study the connection between state campaign finance laws over the last half century and responses to survey questions about political efficacy.

The states are an ideal area to probe this relationship, since laws vary considerably both across the states and over time. In the campaign finance literature others have used this variation to study the electoral effects of campaign finance laws, and recent findings lend credibility to the claim that campaign reforms may influence citizens' efficacy by improving the quality of elections.

For example, Stratmann and Aparicio-Castillo (2002) examine the effects of campaign finance laws on legislative elections in 45 states and over twenty years. Because these authors have a lengthy panel data set (unlike previous studies), they are able to control for unobserved state-specific effects, greatly reducing concerns that state campaign finance regulations are spuriously correlated with measures of electoral competitiveness. ${ }^{9}$ They find that limits on campaign contributions serve to reduce the winning margins of incumbents. However, they do not explore the effects of other types of campaign finance regulations.

We explore the relationship between citizen efficacy and campaign finance laws using individual survey responses from the National Election Studies (NES) from 1952-2000. We conduct a contextual analysis by combining these responses with state-level variables that describe campaign finance regulations and other relevant state political institutions. We find some evidence that public disclosure and restrictions on contributions from organizations improve political efficacy, but fail to find such evidence for other types of campaign finance regulations. In fact, public financing tends to be associated with a decline in efficacy. Overall, no state campaign finance laws appear to have a substantively large impact on the public's perceptions of government. These findings are reinforced by a novel methodological approach to studying state-level trust in government, which is presented in a

\footnotetext{
${ }^{9}$ Gross and Goidel (2003) are also working with a panel data set, but they do not address unobserved state-specific effects in their analysis.
} 
technical appendix.

\section{Political Efficacy}

A voluminous literature addresses the validity and reliability of survey measures for trust and political efficacy (e.g., Campbell, Gurin, and Miller 1954; Miller 1974;

Citrin and Green 1986; Craig, Niemi, and Silver 1990; see Robinson et. al. 1999 for summaries of various measures). In general, there is a consensus that trust, internal efficacy, and external efficacy are three distinct concepts. There is less agreement on the proper ways to measure these concepts. Trust refers to the faith individuals have in the government (Citrin and Muste 1999). Political efficacy refers to the belief that one can have an influence on the political process (Campbell, Gurin, and Miller 1974), although Balch (1974) and others further subdivide political efficacy into "external" and "internal" components. Internal efficacy taps beliefs about whether one can influence the political process, and external efficacy reflects beliefs about whether elected officials are sufficiently responsive to constituents. The upshot of these debates is that measures of efficacy may be "noisy," and this should be kept in mind as the results are presented.

Much political hay has been made of the sharp decline in trust and political efficacy that occurred from the 1950s to the present. For instance, consider one of the most-cited NES questions, used to measure political trust: "How much of the time do you think you can trust the government in Washington to do what is right-just about always, most of the time or only some of the time?" "Trust in government" is defined as answering "just about always" or "most of the time." In 1964, when the question was first asked on a regular basis, 76 percent of respondents trusted the government. By 2000, that number had dropped to 44 percent. There are many culprits identified for the temporal decline in trust at the federal level, including a general increase in cynicism (Alford 2001) and the Vietnam War and 
Watergate (Orren 1997).

Whether or not declines in trust and efficacy materially affect democratic rule is a separate question. For instance, Citrin (1974) and Rosenstone and Hansen (1993) do not find that trust in government influences turnout. In fact, one can argue (as Citrin and Luks 2001 and others do) that some level of mistrust is a net positive for democracy. To the contrary, Brehm and Rahn (1997) posit links between interpersonal trust, civic engagement, and confidence in government, suggesting that low levels of confidence in government may harm interpersonal trust as well as civic engagement.

Direct links between participation and trust or efficacy are only part of the story. Another argument emphasizes the relevance of trust and efficacy's symbolic aspects. Low levels of trust and efficacy are, by virtue of being below some threshold level, threats to self-rule. Therefore, laws should be structured to improve citizen perceptions of government. For the purposes of analysis, we assume that positive perceptions of government are necessary for democratic governance and ascertain whether campaign finance laws influence these perceptions. Only if some substantively meaningful statistical relationship is present does one need to further probe the links among trust, efficacy, and democracy.

\section{Campaign Finance Laws and Political Efficacy: Theoretical Links and Empirical Implications ${ }^{10}$}

The literature on electoral competition, campaign advertising, political efficacy, and trust in government suggests several causal pathways by which campaign finance laws might influence citizens' perceptions about the workings of democracy. To the extent that campaign finance regulations influence electoral competition, or the

\footnotetext{
${ }^{10}$ This section is technical in nature and can be skipped by readers interested only in the main findings.
} 
amount and tone of advertising, it follows that the effects of such regulations will reverberate throughout a larger system of relationships involving competition and advertising. Consequently, voter turnout, trust in government, political interest and even candidate emergence may all ultimately be affected in some way by changes in campaign finance laws.

In this section, we provide a highly simplified structural model of some of these relationships. Our purpose is to provide enough detail to motivate the subsequent empirical approach.

Define:

- $\mathbf{X}=$ a vector of individual characteristics (e.g., age, race, party id, etc.)

- $\mathbf{Z}=$ a vector of characteristics of state institutions (e.g., campaign finance laws, term limits, etc.)

- $E F F I C A C Y=$ an individual's perception of political efficacy or trust in government

- $E X P O S U R E=$ an individual's exposure to campaign messages

- INTEREST = an individual's interest in or knowledge of politics

- $V O T E=$ an individual's vote choice/turnout decision

- $C O M P E T I T I O N=$ competitiveness of elections taking place at the time of a survey

- $S P E N D I N G=$ campaign spending by candidates

A stylized structural model of political efficacy for $i=(1, \ldots, n)$ individuals residing in $s=(1, \ldots, k)$ states may then be articulated as: 


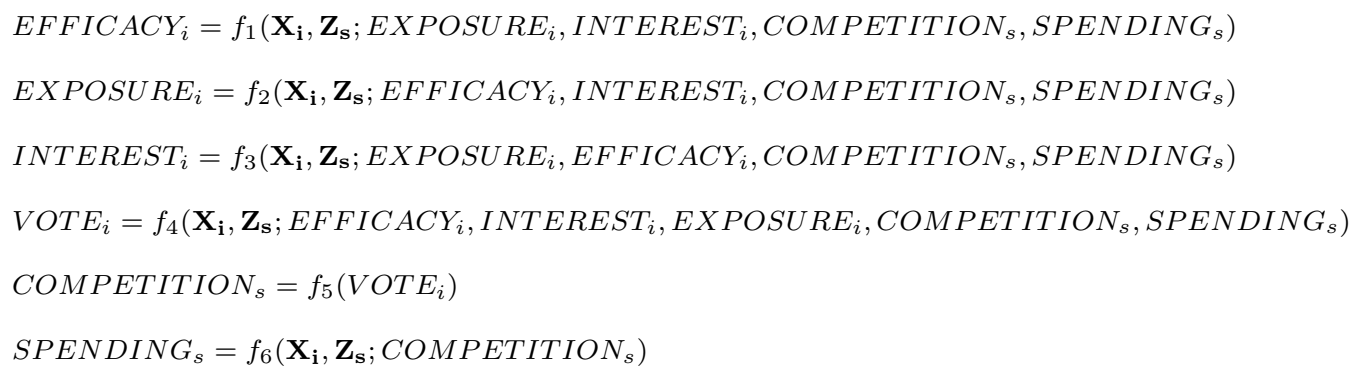

Obviously, we have simplified matters greatly by abstracting away from issues such as the relative amounts of campaign spending by particular candidates or the causes and consequences of candidate quality, tone of advertising, and the like. Even so, the model suggests that there is a complicated and potentially intractable set of inter-relationships in this simultaneous system. In order to fully identify the effects of campaign finance laws (elements of $\mathbf{Z}$ ) on efficacy, exposure, interest, etc. it would be necessary to impose numerous exclusion restrictions on this system. For instance, campaign finance laws likely do not directly influence vote choice, but they do exert an indirect influence on this endogenous variable by influencing campaign spending and competition. Therefore, one exclusion restriction might be to leave campaign finance laws out of equation (4).

We are not sanguine about the prospects of identifying the relationships characterized in the model above. ${ }^{11}$ However, even if such identification were in principle possible, some of the variables listed above (e.g., exposure) may not be available over a long time period or for all states. This absence of data availability also hinders the ability of researchers to probe the effects of political institutions that change infrequently. But all is not lost; the system above can be solved for each of the endogenous variables in terms of the exogenous variables. ${ }^{12}$

\footnotetext{
${ }^{11}$ We are not alone. Rarely are complete systems estimated. For example, Box-Steffensmeier, Grant, and Rudolph (2003) study the impact of campaign finance attitudes on turnout and vote choice but only specify part of what is certainly a larger system of equations.

${ }^{12}$ To give a simple example, consider a two-equation (identified) system as follows: $y_{1}=\beta_{0}+$
} 
In other words, a direct implication of the stylized model is that:

$$
E F F I C A C Y_{i}=g\left(\mathbf{X}_{\mathbf{i}}, \mathbf{Z}_{\mathbf{s}}\right)
$$

In fact, each of the endogenous variables in our stylized structural model can be expressed as functions of only $\mathbf{X}_{\mathbf{i}}$ and $\mathbf{Z}_{\mathbf{s}}$. Further, these reduced form specifications describe the net effect of campaign finance laws (or other elements of $\mathbf{X}$ and $\mathbf{Z}$ ) on efficacy (or other endogenous variables). Therefore, we test the claim that campaign finance reforms increase political efficacy by estimating the reduced-form specification in equation (7). Such estimates are unbiased (or in the case of maximum likelihood, consistent). ${ }^{13}$ This approach also has the practical advantage that limited data for some endogenous variables (e.g., exposure) has no bearing on our ability to estimate the reduced form for equation (7) over a long time period. Finally, for our purposes, the reduced-form approach is desirable because it allows us to exploit the long run variation in state campaign finance laws in order to test the claims made by policy makers and scholars that such reforms have a salutary effect on political efficacy. The drawback of this method is that we cannot study the potential causal pathways by which reform impacts efficacy. We return to this issue in the discussion.

\section{Campaign Finance Laws in the U.S. States}

Campaign finance laws have changed dramatically in the U.S. states in recent decades. Where in 1950 few states had any campaign finance restrictions save for disclosure laws, by 2000 limits on contributions from individuals and organizations

$\beta_{1} X_{1}+\gamma_{1} y_{2}+\epsilon_{1}$ and $y_{2}=\beta_{2}+\beta_{3} X_{2}+\gamma_{2} y_{1}+\epsilon_{2}$. The reduced form can then be written as follows: $y_{1}=\pi_{0}+\pi_{1} X_{1}+\pi_{2} X_{2}+v_{1}$ and $y_{2}=\pi_{3}+\pi_{4} X_{1}+\pi_{5} X_{2}+v_{2}$, where $\pi_{0}=\frac{\beta_{2} \gamma_{1}+\beta_{0}}{1-\gamma_{1} \gamma_{2}}, \pi_{1}=\frac{\beta_{1}}{1-\gamma_{1} \gamma_{2}}$,

$\pi_{2}=\frac{\beta_{3} \gamma_{1}}{1-\gamma_{1} \gamma_{2}}, \pi_{3}=\frac{\beta_{0} \gamma_{2}+\beta_{2}}{1-\gamma_{1} \gamma_{2}}, \pi_{4}=\frac{\beta_{1} \gamma_{2}}{1-\gamma_{1} \gamma_{2}}, \pi_{5}=\frac{\beta_{3}}{1-\gamma_{1} \gamma_{2}}$, and $v_{1}$ and $v_{2}$ are linear combinations of the error terms. Because the right-hand side variables are assumed to be uncorrelated with a typical error term, the reduced-form parameters (the $\pi$ 's) can be estimated in the usual fashion.

${ }^{13}$ For further details, see Maddala (1983) and Kennedy (2003). 
(i.e., corporations, unions, and PACs) were the norm. The trend in state reforms mirrors that at the federal level, where a major wave of changes occurred in the 1970s. State reforms also picked up steam in the 1990s, with more than one-third of states altering their laws during this period (Malbin and Gais 1998). We are in what might be called an era of "mature" campaign finance regulation, since all states have disclosure laws on the books, and most states have some restrictions on contributions.

We focus here on contributions to candidates rather than to parties, as information on the latter is not readily available for the full time period under study. We consider disclosure laws, contribution limits on corporations, contribution limits on individuals, the presence of public financing tied to voluntary expenditure limits, and mandatory expenditure limits in place prior to the Supreme Court's ruling that such limits were unconstitutional. Figure 1 depicts the number of states with each type of campaign finance law.

While there are several ways to categorize and measure state-level laws, in this case simpler is better. We measure the presence or absence of particular types of laws, such as contribution limits and public financing. Using specific dollar amounts leads one into a morass, in part because states greatly differ in many respects, including cost-of-living, wealth, and the cost of media markets. Put concretely, does a $\$ 1000$ limit on individual contributions to a candidate mean the same thing in Arkansas as it does in California? If not, how would one compare specific limits across states? Other aspects of campaign finance law, such as enforcement quality, suffer from similar problems. The presence or absence of particular laws, on the other hand, can be clearly measured and is directly comparable across states. 


\section{$5 \quad$ Data and Methods}

The biennial National Election Studies has been asking questions on trust and efficacy for five decades. ${ }^{14}$ We focus on political efficacy because the battery of NES trust questions asks specifically about the federal government, while questions regarding efficacy ask about government generally. This paper therefore uses the best available temporal data. ${ }^{15}$ Unfortunately, this data limitation means that we cannot reach definitive conclusions with respect to trust. This does not alter the importance of our findings, since concepts like trust, faith, confidence, and efficacy are often used interchangeably in popular (and legal) usage. ${ }^{16}$

Individual-level data is from the 1948-2000 NES Cumulative Data File. State-level data is taken from The Book of the States, Campaign Finance Law, and other public sources. Using state-level variables when working with individual-level variables requires caution. For instance, because the National Election Studies does not include representative state samples, it is not possible to make claims about a specific state and how it has changed over time. Rather, residing in a state should be viewed as a "treatment" on the individuals, with state institutional features, including campaign finance laws, representing treatment effects similar to those we might observe in medical experiments. In this way, we can ascertain whether living in a state with particular campaign finance laws influences one's perceptions of government. ${ }^{17}$

We utilize three measures of efficacy that have been asked in the National Election Studies over time. These dependent variables are dichotomous and are

\footnotetext{
${ }^{14}$ Importantly, this is not panel data, since the respondents differ each time the survey is administered. Rather, it is pooled cross-sectional data.

${ }^{15}$ One other drawback of the data is that the dependent variable reflects questions asking about government generally, not state government specifically, thereby creating a noisy dependent variable.

${ }^{16} \mathrm{We}$ do, however, attempt to capture state-level trust using the 1996 NES. See the appendix.

${ }^{17} \mathrm{NES}$-provided weights ensure that the analysis of campaign finance laws is accurate with respect to subgroups. Since in the NES sample the number of individuals surveyed in a state is typically related to that state's population, we have also verified that there is a negligible relationship between the population of a state and the presence of campaign finance laws.
} 
coded such that a value of one indicates a more favorable disposition toward government (i.e., disagreeing with the statements). The percent disagreeing for each question appears in parentheses. The first two questions, which tap external efficacy, are most directly relevant for the issue of campaign finance reform. Figure 2 summarizes the year-to-year responses for the entire NES sample.

- People like me don't have any say about what the government does. $(60 \%$ disagree)

- Public officials don't care much what people like me think. (50\% disagree)

- Sometimes politics and government seem so complicated that a person like me can't really understand what's going on. (30\% disagree)

Because we are working with binary dependent variables, probit models are estimated. ${ }^{18}$ These models are utilized when working with dependent variables that can take on two values. When appropriately converted, the coefficients on the independent variables tell us how much a one-unit change in the independent variable influences the likelihood of answering positively to a question. ${ }^{19}$ In our case, we are interested in the impact of implementing a campaign finance law, and in the results section we discuss the impact of these laws on the various efficacy measures.

Several state-level variables are included in the analysis to control for other features of a state that may influence citizen perceptions as well as changes in campaign finance law. These include indicators for the presence of the citizen initiative, gubernatorial or legislative term limits, whether a poll tax or literacy tests are necessary to vote, and whether easy voting registration is present (i.e., same day or no advance registration required). ${ }^{20}$ We also include state dummy

\footnotetext{
${ }^{18}$ Because multiple survey respondents from each state and year in the sample receive the same "treatment" in the form of campaign finance and other state-level laws, the observations from each state are unlikely to be independent. This may cause standard errors to be underestimated. We therefore adjust standard errors for the clustering of observations within state and year using a modification of White's (1980) standard errors developed by Rogers (1993).

${ }^{19}$ The coefficients are not directly interpretable without a transformation.

${ }^{20}$ Poll taxes and literacy tests are of course now outlawed; however, they were present for some years in our sample.
} 
variables to control for unobserved heterogeneity across states; this is particularly important given that state campaign finance laws may be passed precisely in those states with chronically low levels of trust or efficacy. Year dummy variables are included in the analysis to control for features of particular survey years that may influence survey responses. ${ }^{21}$

Five dichotomous campaign finance variables represent the laws in each state. ${ }^{22}$ These are indicators for the presence of

1. public disclosure of campaign contributions

2. limits on contributions by organizations only

3. limits on contributions by organizations and individuals

4. public subsidies to candidates that abide by expenditure limits

5. mandatory expenditure limits in place prior to the 1976 Buckley $v$. Valeo decision outlawing such limits.

To investigate whether there is a delay before campaign finance laws impact efficacy, we examine models that include four-year lags of these laws. We also include four-year leads of laws in some specifications to see whether efficacy is related to future campaign finance laws, which is possible if low levels of efficacy usher in reform.

Individual-level controls include education (grade school, high school, some college, college or more), age, age squared, income (measured in percentiles, with a coding of 1 representing the 1 st to 16 th percentile, 2 the 17 th to 33 rd percentile, 3 the 34 th to 67 th percentile, 4 the 68 th to 95 th percentile, and 5 the 96 th to

\footnotetext{
${ }^{21}$ When working with data of this type, it is also possible to use hierarchical linear modeling (HLM), which enables the researcher to offer theoretical explanations for differences in behavior across levels. However, HLM requires many more assumptions than standard regression or maximum likelihood techniques, and it is more sensitive to measurement error (Bryk and Raudenbush 1992; Steenbergen and Jones 2002). For our purposes, then, HLM is not the best method.

${ }^{22}$ By defining the variables in this way, we avoid concerns about multicollinearity, especially between limits on contributions to individuals and organizations. This was verified by conducting a variety of diagnostic tests for the campaign finance variables. We do not create an index of laws because we do not expect their effects to be additive. This is borne out in the empirical analysis.
} 
99th percentile), unemployment, race, gender, and the strength of one's partisan affiliation (ranging from 1 - 4). ${ }^{23}$ We include strength of affiliation because we expect that individuals with strong partisan ties are more likely to feel efficacious, regardless of whether they are Republicans or Democrats. In addition, we include controls for Republican and Democratic party identification. We also interact party identification and year to assess whether there are any national-level partisan trends that may cause Democrats or Republicans to feel less efficacious. Additional variables include unified state Democratic government and unified state Republican government, as well as interaction terms for Democratic respondent living in a unified Democratic state, Democratic respondent living in a unified Republican state, Republican respondent living in a unified Republican state, and Republican respondent living in a unified Democratic state. These interactions capture whether affiliating with an out-of-power party makes one feel less efficacious. Summary statistics and details regarding the years and states included in each specification appear in Table 1.

\section{$6 \quad$ Results}

In Table 2 we present the estimated probit coefficients for each question on political efficacy. Year and state dummy variables are both jointly significant. The importance of the state dummy variables suggests that they are controlling for factors that might otherwise bias our estimates of the effects of campaign finance laws. ${ }^{24}$ Neither lags nor leads of the campaign finance variables are jointly

\footnotetext{
${ }^{23} \mathrm{~A}$ host of other variables might be expected to have a direct influence on efficacy (e.g., campaign spending, financial situation, exposure to news sources, etc.); however, such variables are either not in the dataset for the entire period or are in turn functions of our included covariates. In other words, where other authors, such as Coleman and Manna (2000) have sought to estimate the structural equation relating campaign spending to efficacy, we estimate the reduced form effect of state campaign finance laws. Consequently, we include only exogenous control variables in our model specification. See section 3 for further details.

${ }^{24}$ We also examined the coefficients on the state dummy variables for patterns that suggest that "reform" states were systematically different from laissez-faire states, but none emerged.
} 
significant at the .10 level (using Wald tests in separate specifications), thereby mitigating concerns about endogeneity or delayed effects for those variables.

In general, the individual-level controls are statistically significant. The more educated tend to have a more favorable view of government. The same positive relationship exists for income and strength of partisanship. Gender has mixed effects, while nonwhites are less likely to feel efficacious than whites. State-level institutional controls have mixed effects on efficacy, and these effects are typically not statistically significant. Overall, the explanatory power of the controls is modest, leaving much variation for campaign laws to explain. ${ }^{25}$

The first efficacy measure is "Do people have a say?" Public disclosure has a positive and statistically significant coefficient, as does the presence of organizational but not individual limits. Adding individual limits in a state decreases efficacy, though this result is not statistically significant. The same is true for mandatory expenditure limits. Public funding, however, has a statistically significant negative effect on efficacy.

For the question "Do officials care?," public disclosure is once again positively and significantly associated with a positive response, and public funding is negatively and significantly associated with feeling efficacious. No other campaign finance variables have a statistically significant effect in this specification. Finally, the third measure, "Is politics too complicated," yields no statistically significant campaign finance variables.

In order to illustrate the substantive importance of campaign finance laws, we use our model to calculate the change in the probability that an individual reports a favorable view of government. Table 3 includes estimates of the effects of campaign finance laws on the change in the probability that an individual has a favorable view of government. This exercise requires the selection of a baseline probability

\footnotetext{
${ }^{25}$ The pseudo- $R^{2}$ measure, while imperfect, is on the order of .10 in most cases when just controls are included in the estimation.
} 
for comparison; we consider the hypothetical case of an individual with a baseline probability of responding favorably to each efficacy measure that is equal to the mean for that measure. For example, in column one of Table 3, the addition of a public disclosure law raises the probability that our hypothetical individual will respond that people "have a say" from 60 percent to 63 percent.

The results in Table 3 show that none of the campaign finance variables consistently has a statistically significant effect on every measure of political efficacy. There may be some modest improvement in efficacy from disclosure laws, and perhaps even limits on contributions from organizations. However, the evidence showing a negative effect of public financing is at least as strong. Finally, there is no evidence that either mandatory expenditure limits or limits on individual contributions have any appreciable impact on efficacy. ${ }^{26}$

\section{Discussion}

Judicial and legislative actors have long assumed that campaign finance reforms can and do influence public perceptions about the workings of democracy. Until now, there has been no systematic study of the presumed link between campaign finance regulations and public opinion. While ours is surely not the last word on the subject, our findings are in stark contrast to what has been accepted as the common sense and self-evident connection between campaign reform and the perceived integrity of the American democratic process.

This is not to say that the causal relationship identified by policymakers does not exist. But even if it does, several recent studies suggest that there may be important countervailing salutary influences of campaign spending, as well. Consequently,

\footnotetext{
${ }^{26}$ We also conduct a robustness check by creating an index of responses to the dependent variables, from 0-3, and estimating an ordered probit. In this specification, organizational contribution limits have a positive and statistically significant effect on efficacy, and public financing has a negative and statistically significant effect. No other laws have statistically significant effects. As in the main specification, all effects are substantively modest.
} 
the net effects of campaign finance regulations on political efficacy appear muted or even contrary to expectations. ${ }^{27}$ These countervailing forces may explain the two apparent puzzles in our findings. First, why might disclosure laws have such a positive influence on efficacy while public financing has negative effects? Second, why might organizational contribution limits improve efficacy while individual limits have little influence or perhaps even negatively impact efficacy?

The "Brandeis view," that sunshine is the best disinfectant, suggests that states with disclosure are providing their citizens with the necessary information to be better citizens. Disclosure laws probably do not reduce overall campaign spending, so they do not reduce the positive aspects of political advertising. On the other hand, public financing schemes are typically devised to limit overall expenditures, so they may have a greater negative impact on the beneficial aspects of political expenditures. In addition, public financing may be predicated on false promises for a better democratic process. When the smoke clears and "politics as usual" returns after reform, individuals may become even more disenchanted with their government. ${ }^{28}$ Therefore, the apparent counterintuitive finding that disclosure and public financing work in opposite directions on political efficacy is quite plausible. This is potentially the most policy-relevant finding, as well, since public financing is the type of reform most likely to be implemented in jurisdictions with "mature" regulatory regimes.

Our results regarding the effects of contribution limits are less robust, but likewise suggest the presence of countervailing influences of campaign finance on political efficacy. The findings suggest that individual limits do not improve efficacy (and may harm efficacy), while contribution limits on organizations appear to have a nonnegative influence on efficacy. One reason for this relationship may be that

\footnotetext{
${ }^{27}$ This also suggests the importance of further work probing the structural system discussed earlier.

${ }^{28} \mathrm{Of}$ course, it is possible that states with low trust and efficacy adopt campaign finance reforms. However, our analysis accounts for this possibility both by incorporating state indicators and by examining the lags and leads of the laws.
} 
corporate or union contributions represent "interested money," whereas individual contributions are viewed as more benign. Hence, when corporate contributions are limited, individuals cheer, but when individual contributions are limited, individuals jeer. Another possibility is that the increased competitiveness in states with limits on organizational contributions may in turn increase efficacy. Because not all laws associated with increased competitiveness improve efficacy, this is clearly only part of any complete explanation. And importantly, the results for contribution limits, even when statistically significant, are substantively modest.

An alternative perspective is that political efficacy is not greatly improved by public financing or limits on contributions because we have not enacted the right types of limits or public financing systems. For instance, Ackerman and Ayres propose the creation of "Patriot Dollars" and a secret "donation booth" to overcome the problems inherent in existing campaign finance regimes (2002). Under their plan, citizens would be given funds to give to candidates of their choice, secretly, and similarly individuals could give unlimited contributions to candidates of their choice, but only anonymously. Ackerman and Ayres suggest that this improves on the existing system because it avoids the inevitable attempts to skirt limits that have arisen after nearly all reforms to date. Of course, there is no guarantee that their plan (or any other, for that matter) will work as intended. In fact, it is not an exaggeration to state that most of the consequences of campaign finance law since the 1970s have been unintended rather than the result of careful planning. ${ }^{29}$

Another criticism of our findings might be that because citizens have displayed a remarkable lack of interest in and knowledge of campaign finance reform (Primo 2002; Mayer 2001), it should not be surprising that there is little relationship between laws and levels of efficacy or trust. This argument has intuitive appeal but fails to acknowledge that (a) the laws-trust-efficacy link has been used extensively in jurisprudence and is viewed as self-evident and (b) more than just knowledge of

\footnotetext{
${ }^{29}$ A parallel can be drawn to ethics laws. See Rosenson (2003) for a discussion.
} 
the laws may influence efficacy. Whatever influence the laws have on the political system in a state is captured in the statistical analysis by the law variables.

Knowledge of the laws is not a necessary condition for the laws to have an effect, as our earlier system of equations indicates. For instance, campaign finance laws may affect campaign spending, which in turn influences exposure to advertising, which in turn influences efficacy. Further, Primo (2002) has shown that attentive individuals tend to be more skeptical of campaign financing than those who pay little attention to money in politics, and Ansolabehere, Snowberg, and Snyder (2005) show that more attentive individuals overestimate the amount of money in politics. If anything, then, ignorance of the laws may very well be bliss.

This study suggests profitable future directions for research. Further work should probe the complex web of interrelationships in campaign finance to consider possible causal pathways that lead to these small effects. In addition, a limited number of surveys ask directly about state-level trust or efficacy. A study based on these surveys would trade off a longer time span of data for a less noisy dependent variable, thereby offering another way to study the question addressed in this article.

In closing, this article makes a theoretical contribution to the study of attitudes toward government and offers the first systematic test of the link between campaign finance laws and citizen perceptions of democratic rule. We find that the effect of campaign finance laws is sometimes perverse, rarely positive, and never more than modest. Given the importance placed on public opinion for the development of campaign finance law, it is remarkable that we have found so little evidence that citizens are influenced by the campaign finance laws of their state.

\section{References}

Ackerman, Bruce, and Ian Ayres. 2002. Voting With Dollars. New Haven: Yale University Press.

Alford, John R. 2001. "We're All in This Together: The Decline of Trust in 
Government, 1958-1996." In What is it About Government That Americans Dislike?, ed. John R. Hibbing and Elizabeth Theiss-Morse. Cambridge: Cambridge University Press, pp. 28-46.

Ansolabehere, Stephen, Erik C. Snowberg, and James M. Snyder, Jr. 2005. "Unrepresentative Information: The Case of Newspaper Reporting on Campaign Finance." Public Opinion Quarterly 69:213-231.

Balch, George I. 1974. "Multiple Indicators in Survey Research: The Concept 'Sense of Political Efficacy."' Political Methodology 1:1-43.

Book of the States. Various Years. Lexington, KY: Council of State Governments.

Box-Steffensmeier, Janet M., J. Tobin Grant, and Thomas J. Rudolph. 2003. "The Effects of Campaign Finance Attitudes on Turnout and Vote Choice in the 2000 Elections." In Models of Voting in Presidential Elections., ed. Herbert F. Weisberg and Clyde Wilcox. Stanford: Stanford University Press, pp. 85-102.

Brehm, John, and Wendy Rahn. 1997. "Individual-Level Evidence for the Causes and Consequences of Social Capital." American Journal of Political Science 41(3):999-1023.

Breyer, Stephen. 2004. "Our Democratic Constitution." Harvard University Tanner Lectures on Human Values 2004-2005, November 17-19.

Bryk, Anthony S., and Stephen W. Raudenbush. 1992. Hierarchical Linear Models. Newbury Park, CA: Sage.

Bronars, Stephen G., and John R. Lott. 1998. "Do Campaign Contributions Alter How a Politician Votes? Or, Do Donors Support Candidates Who Value the Same Things That They Do?" Journal of Law and Economics 40:317-350.

Buckley v. Valeo. 1976. 424 U.S. 1.

Campbell, Angus, Gerald Gurin, and Warren E. Miller. 1954. The Voter Decides. Evanston, IL: Row, Peterson.

Citrin, Jack. 1974. "Comment: The Political Relevance of Trust in Government." American Political Science Review 68:973-988.

Citrin, Jack, and Donald Philip Green. 1986. "Presidential Leadership and the Resurgence of Trust in Government." British Journal of Political Science 16:431-453.

Citrin, Jack, and Samantha Luks. 2001. "Political Trust Revisited: Deja Vu All Over Again?" In What Is It About Government That Americans Dislike?, ed. John R. Hibbing and Elizabeth Theiss-Morse. Cambridge: Cambridge University Press, pp. 9-27. 
Citrin, Jack, and Christopher Muste. 1999. "Trust in Government." In Measures of Political Attitudes, ed. John P. Robinson, Phillip R. Shaver, and Lawrence S. Wrightman. San Diego: Academic Press, pp. 465-532.

Coleman, John J., and Paul F. Manna. 2000. "Congressional Campaign Spending and the Quality of Democracy." Journal of Politics 62(3):757-789.

Congressional Record. 1999. Vol. 145, No. 139, S12804, October 14.

Congressional Research Service. Various Years. Campaign Finance Law. Washington, DC: National Clearinghouse on Election Administration.

Craig, Stephen C., Richard G. Niemi, and Glenn E. Silver. 1990. "Political Efficacy and Trust: A Report on the NES Pilot Study Items." Political Behavior 12:289-314.

CSC v. Letter Carriers. 1973. 413 U.S. 548.

Freedman, Paul, Michael Franz, and Kenneth Goldstein. 2004. "Campaign Advertising and Democratic Citizenship." American Journal of Political Science 48(4):723-741.

Gerber, Alan 1998. "Estimating the Effect of Campaign Spending on Senate Election Outcomes Using Instrumental Variables." American Political Science Review 92(2):401-411.

Goidel, Robert K., Donald A. Gross, and Todd G. Shields. 1999. Money Matters. Lanham, MD: Rowman \& Littlefield.

Grant, J. Tobin, and Thomas J. Rudolph. 2004. Expression vs. Equality: The Politics of Campaign Finance Reform. Columbus: Ohio State University Press.

Gross, Donald A., and Robert K. Goidel. 2003. The States of Campaign Finance Reform. Columbus: Ohio State University Press.

Hibbing, John R., and Elizabeth Theiss-Morse. 1995. Congress as Public Enemy. Cambridge: Cambridge University Press.

Jacobus v. State of Alaska. 2003.

Kennedy, Peter. 2003. A Guide to Econometrics. Cambridge, MA: MIT Press.

Levitt, Steven. 1994. "Using Repeat Challengers to Estimate the Effects of Campaign Spending on Election Outcomes in the U.S. House." Journal of Political Economy 102:777-798.

Levitt, Steven. 1998. "Are PACs Trying to Influence Politicians or Voters?" Economics and Politics 10(1):9-35.

Maddala, G.S. 1983. Limited-Dependent and Qualitative Variables in Econometrics. Cambridge: Cambridge University Press. 
Malbin, Michael J., and Thomas L. Gais. 1998. The Day After Reform: Sobering Campaign Finance Lessons form the American States. Albany, NY: Rockefeller Institute Press.

Mann, Thomas E. 2003. "Linking Knowledge and Action: Political Science and Campaign Finance Reform." Perspectives on Politics 1(1):69-84.

Mayer, William G. 2001. "Public Attitudes on Campaign Finance." In A User's Guide to Campaign Finance Reform, ed. Gerald C. Lubenow. Lanham, MD: Rowman \& Littlefield, pp. 47-69.

McConnell v. FEC. 2003. 540 U.S. 93.

Miller, Arthur H. 1974. "Political Issues and Trust in Government: 1964-1970." American Political Science Review 68:951-972.

Milyo, Jeff, David Primo, and Tim Groseclose. 2003. "The Effects of State Campaign Finance Regulation on Turnout, Electoral Competition, and Partisan Advantage in Gubernatorial Elections, 1949-1998." Paper Presented at the Annual Meeting of the Public Choice Society, March 3-6.

Nixon v Shrink Missouri Government PAC. 2000. 528 U.S. 377.

Orren, Gary. 1997. "Fall From Grace: The Public's Loss of Faith in Government." In Why People Don't Trust Government, ed. Joseph S. Nye, Jr., Philip D. Zelikow and David C. King. Cambridge: Harvard University Press, pp. 77-107.

Persily, Nathaniel, and Kelli Lammie. 2004. "Perceptions of Corruption and Campaign Finance: When Public Opinion Determines Constitutional Law." Pennsylvania Law Review 153:119-180.

Primo, David M. 2002. "Campaign Finance and Public Opinion: Reformers Versus Reality." Independent Review 7(2):207-219.

Robinson, John P., Phillip R. Shaver, and Lawrence S. Wrightsman. 1999. Measures of Political Attitudes. San Diego: Academic Press.

Rogers, William. 1993. "sg17: Regression standard errors in clustered samples." Stata Technical Bulletin 13:19-23.

Rosenson, Beth A. 2003. "The Effects of Ethics Laws on the Recruitment, Retention, and Occupations of State Legislators." Paper Presented at the Annual Meeting of the American Political Science Association.

Rosenstone, Steven J., and John Mark Hansen. 1993. Mobilization, Participation, and Democracy in America. New York: Macmillan.

Steenbergen, Marco R., and Bradford S. Jones. 2002. "Modeling Multilevel Data Structures." American Journal of Political Science 46:218-237. 
Stratmann, Thomas. 1998. "The Market for Congressional Votes: Is the Timing of Contributions Everything?" Journal of Law and Economics 41:85-114.

Stratmann, Thomas, and Francisco J. Aparicio-Castillo. 2002. "Competition Policy for Elections: Do Campaign Contribution Limits Matter?" Paper Presented at the Second Annual Conference on State Politics and Policy, May 24-25.

Vlahos, Kelley Beaucar. 2003. "Campaign Finance Law Ruling Expected Soon." Fox News, March 12. Accessed August 10, 2003, at http : //www.foxnews.com/story/0, 2933, 80842, 00.html.

Weber, Ronald E. 1999. "The Quality of State Legislative Representation: A Critical Assessment." Journal of Politics 61:609-627.

White, Halbert. 1980. "A Heteroskedasticity-Consistent Covariance Matrix Estimator and a Direct Test for Heteroskedasticity." Econometrica 48:817-830. 


\section{Table 1. Summary Statistics for Efficacy Analysis}

Variable Mean

Have a Say? $\quad .60$

Officials Care? $\quad .50$

Complicated? $\quad .30$

Public disclosure of contributions $\quad .89$

Contribution limits (organizations only) $\quad .40$

Contribution limits (orgs. and ind.) $\quad .29$

Public funding $\quad .08$

Mandatory expenditure limits $\quad .24$

Income $=2 \quad .17$

Income $=3$

Income $=4 \quad 29$

Income $=5 \quad 0.05$

Unemployed $\quad .06$

High School $\quad .48$

Some College $\quad .20$

College $\quad .17$

Age $\quad 44.90$

Age Squared $\quad 2302.39$

Nonwhite $\quad .15$

Female $\quad .55$

Partisan Strength $\quad 2.86$

Democrat $\quad .53$

Republican $\quad .36$

Unified Dem. Govt. $\quad .36$

Unified Rep. Govt. $\quad .14$

Dem. x Unified Dem. $\quad .21$

Dem. x Unified Rep. $\quad .07$

Rep. x Unified Rep. $\quad .06$

Rep. x Unified Dem.

Citizen Initiative $\quad .44$

Gub. Term Limits $\quad .53$

Leg. Term Limits $\quad .08$

Poll Tax $\quad .03$

Literacy Test $\quad .08$

Easy Registration $\quad 02$

The NES was administered every two years beginning in 1948, with the exception of 1950. The "have a say" question was not asked in 1948, 1954, 1958, 1962, and 1986; N=30,034. The "officials care" question was not asked in 1948, 1954, 1958, and 1962; N=30,189. The "complicated" question was not asked in 1948, 1954, 1958, 1962, 1982, 1986; N=28,810. The following states were not included in the analysis due to a lack of observations: Alaska, Hawaii, Montana, and Vermont. In addition, Rhode Island was not included in the "have a say" or "complicated" analyses due to a lack of observations. Observations with missing data are excluded from the analysis. The summary statistics presented for the independent variables $(\mathrm{N}=30,034)$ are based on the "have a say" specification; they do not change in any meaningful way in the other specifications. We present only the means because all variables (except for age, age squared, and partisan strength) are dichotomous. The standard deviations for the exceptions are as follows: age (16.91), age squared (1675.98), and partisan strength (.97). 


\section{Table 2. Political Efficacy and Campaign Finance Laws}

\begin{tabular}{|c|c|c|c|c|c|c|}
\hline Variable & Have & Say? & Officials & Care? & Compl & cated? \\
\hline & Coef. & z-stat & Coef. & z-stat & Coef. & Z-stat \\
\hline Public disclosure of contributions & .074 & 1.72 & .074 & 1.86 & .004 & .10 \\
\hline Contribution limits (organizations only) & .099 & 2.41 & .021 & 0.55 & .050 & 1.13 \\
\hline Contribution limits (orgs. and ind.) & -.032 & .80 & .017 & 0.44 & -.033 & .80 \\
\hline Public funding & -.130 & 2.64 & -.104 & 2.17 & -.065 & 1.33 \\
\hline Mandatory expenditure limits & -.019 & .51 & -.009 & .25 & -.052 & 1.40 \\
\hline Income $=2$ & .079 & 2.90 & .058 & 2.16 & .055 & 1.58 \\
\hline Income $=3$ & .167 & 6.39 & .171 & 6.26 & .080 & 2.40 \\
\hline Income $=4$ & .256 & 8.64 & .265 & 8.94 & .193 & 5.59 \\
\hline Income $=5$ & .375 & 8.77 & .484 & 11.91 & .370 & 7.73 \\
\hline Unemployed & -.080 & 2.15 & -.066 & 1.83 & .025 & .62 \\
\hline High School & .380 & 13.49 & .427 & 16.16 & .393 & 11.98 \\
\hline Some College & .697 & 20.36 & .676 & 20.72 & .836 & 22.09 \\
\hline College & .918 & 25.96 & .929 & 28.29 & 1.136 & 28.91 \\
\hline Age & .004 & 1.51 & -.001 & .22 & .006 & 1.62 \\
\hline Age Squared & -.000 & 2.04 & -.000 & 1.02 & -.000 & 2.25 \\
\hline Nonwhite & -.074 & 2.86 & -.145 & 5.59 & -.026 & .89 \\
\hline Female & -.035 & 2.10 & .045 & 2.64 & -.363 & 21.04 \\
\hline Partisan Strength & .093 & 7.91 & .109 & 9.14 & .087 & 6.96 \\
\hline Democrat & -.045 & .37 & .300 & 1.47 & .108 & .88 \\
\hline Republican & .057 & .40 & -.147 & 1.27 & -.260 & 1.79 \\
\hline Unified Dem. Govt. & -.007 & .13 & -.121 & 2.08 & .013 & .21 \\
\hline Unified Rep. Govt. & .043 & .52 & .012 & 0.15 & -.071 & .83 \\
\hline Dem. x Unified Dem. & -.012 & .20 & .138 & 2.30 & -.045 & .69 \\
\hline Dem. x Unified Rep. & .051 & .56 & .016 & 0.18 & .075 & .80 \\
\hline Rep. x Unified Rep. & .058 & .59 & .108 & 1.18 & .114 & 1.14 \\
\hline Rep. x Unified Dem. & .036 & .57 & .059 & 0.93 & .042 & .63 \\
\hline Citizen Initiative & -.032 & .47 & -.048 & .71 & -.096 & 1.77 \\
\hline Gub. Term Limits & -.056 & 1.09 & -.143 & 3.02 & .009 & .20 \\
\hline Leg. Term Limits & -.062 & 1.30 & -.037 & .85 & .053 & 1.18 \\
\hline Poll Tax & -.032 & .50 & -.199 & 2.71 & -.071 & 1.15 \\
\hline Literacy Test & -.043 & .93 & -.036 & .74 & -.076 & 1.52 \\
\hline Easy Registration & -.015 & .19 & .018 & 0.24 & .017 & .18 \\
\hline Constant & -.923 & 5.21 & -1.70 & 8.27 & -1.34 & 7.28 \\
\hline $\mathrm{N}$ & 30,034 & & 30,189 & & 28,810 & \\
\hline
\end{tabular}

All probit specifications include state and year dummy variables with robust standard errors adjusted for clustering within state and year, as well as interaction terms for year and party identification. Absolute value of z-statistics are presented in the table. "Have a say?" refers to whether or not individuals believe that they have a say in government; "Officials Care" refers to whether individuals believe that officials care what people like them think; and "Complicated?" refers to whether individuals find politics to be too complicated. In all cases, the dependent variable is coded 1 for a response indicating that an individual feels efficacious, and 0 otherwise. 


\section{Table 3. Marginal Effects of Campaign Finance Laws on Political Efficacy}

\begin{tabular}{|c|c|c|c|}
\hline Variable & Have a Say? & Officials Care? & Too Complicated? \\
\hline Mean of dependent variable & .60 & .50 & .30 \\
\hline $\begin{array}{l}\text { Change in probability from the pres } \\
\text { Public disclosure } \\
\text { of campaign contributions }\end{array}$ & $\begin{array}{l}\text { e of campaign } \\
.03^{*}\end{array}$ & $\begin{array}{r}\text { ance laws } \\
.03^{*}\end{array}$ & .00 \\
\hline $\begin{array}{l}\text { Limits on contributions } \\
\text { from organizations only }\end{array}$ & $.04^{* *}$ & .01 & .02 \\
\hline $\begin{array}{l}\text { Limits on contributions } \\
\text { from organizations and individuals }\end{array}$ & -.01 & .01 & -.01 \\
\hline $\begin{array}{l}\text { Public funding of candidates } \\
\text { conditional on expenditure limits }\end{array}$ & $-.05^{* * *}$ & $-.04^{* *}$ & -.03 \\
\hline $\begin{array}{l}\text { Mandatory expenditure limits } \\
\text { (pre-Buckley) }\end{array}$ & -.01 & .00 & -.02 \\
\hline
\end{tabular}

The change in probability of a favorable response from the implementation of a particular law (or set of laws) is derived from the estimated coefficients in Table 2, where all changes are calculated at the mean of the dependent variable. ${ }^{*} p<.10$, ${ }^{* *} p<.05$, and ${ }^{* * *} p<.01$. 
29

Figure 1: Campaign Finance Laws in the U.S. States, 1950-2000

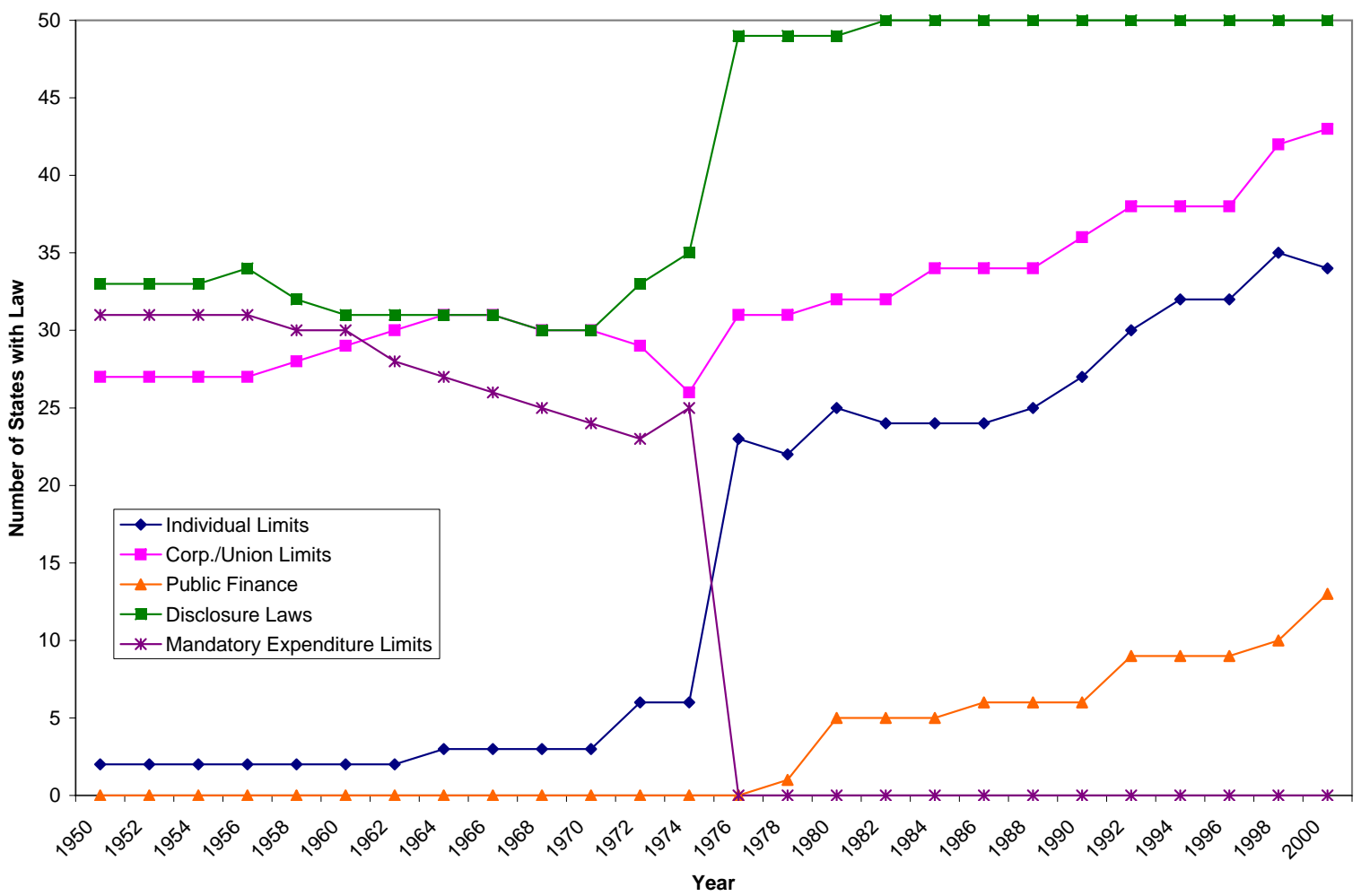


Figure 2: Political Efficacy, 1952-2000

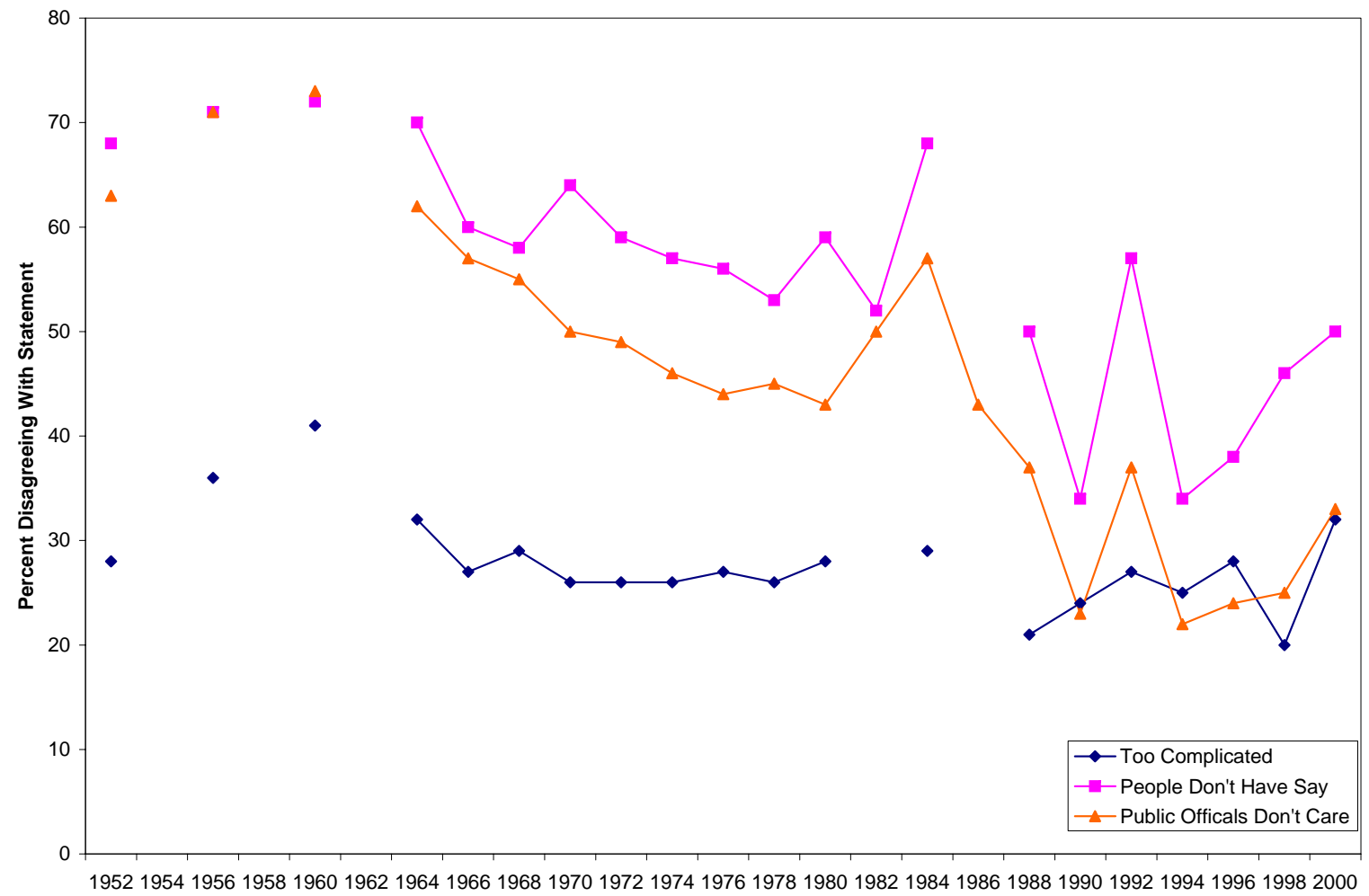




\section{Appendix: An Alternative Approach}

One criticism of the test in the main text is that the questions are not directly asking about state government. To address this, we develop a method for estimating a state-specific trust measure using a question from the NES. Consider two regression equations estimating the effect of campaign finance laws on trust in the state and federal governments, where each error term includes a common individual-level fixed effect, fe, capturing the tendency to mistrust government at all levels. Let Fedtrust be a latent variable measuring trust in the federal government and Statetrust be a latent variable measuring trust in the state government. Let $i$ index the $k$ covariates appearing in both equations, and $j$ index the campaign finance laws that may affect state trust in government. (By construction, we assume that state campaign finance laws have no effect on federal trust in government.) Finally, let $y^{*}$ be a continuous latent variable that measures the difference in an individual's trust in the federal and state governments.

$$
\begin{aligned}
\text { Fedtrust } & =a_{0}+\sum_{i=1}^{k} a_{i} x_{i}+v_{1} \\
\text { Statetrust } & =b_{0}+\sum_{i=1}^{k} b_{i} x_{i}+\sum_{j=1}^{m} b_{j} \text { statela }_{j}+v_{2},
\end{aligned}
$$

where $v_{1}=\epsilon_{1}+f e, v_{2}=\epsilon_{2}+f e, \operatorname{cov}\left(\epsilon_{1}, \epsilon_{2}\right)=0$, and $\epsilon_{1}$ and $\epsilon_{2}$ are distributed i.i.d. normal. Subtracting equation 1 from equation 2 gives

$$
\text { Statetrust }- \text { Fedtrust }=\left(b_{0}-a_{0}\right)+\sum_{i=1}^{k}\left(b_{i}-a_{i}\right) x_{i}+\sum_{j=1}^{m} b_{j} \text { statelaw }_{j}+\left(\epsilon_{2}-\epsilon_{1}\right) .
$$

The dependent variable is now equivalent to $y^{*}$. Substituting gives

$$
y^{*}=\left(b_{0}-a_{0}\right)+\sum_{i=1}^{k}\left(b_{i}-a_{i}\right) x_{i}+\sum_{j=1}^{m} b_{j} \text { statelaw }_{j}+\left(\epsilon_{2}-\epsilon_{1}\right)
$$

If we are able to observe whether $y^{*}$ is positive or negative, then this equation can be estimated using a standard probit or logit, with the dependent variable being 
coded one if $y^{*}>0$ and zero otherwise. This will allow us to estimate directly the

effects of state laws on trust in government, since $\sum_{j=1}^{m} b_{j}$ and their standard errors can be estimated via the combined equation. The remaining coefficients capture the effect of an independent variable on the difference between state-level and federal-level government trust. Therefore, in this estimation, we are only able to measure the direct effect of campaign finance law (and other state-level institutions) on trust in state government. Standard errors need to be adjusted to account for clustering in the data (i.e., multiple observations from the same state). To implement this method, all we need is a survey question that asks respondents to rank-order their level of trust in the state and federal governments. Fortunately, such a question is available.

The 1996 National Election Studies asks two questions regarding relative levels of trust in the state and federal governments. These questions are used to assess the effects of campaign finance laws on trust in state government.

- We find that people differ in how much faith and confidence they have in various levels of government in this country. In your case, do you have more faith and confidence in the national government, the government of this state, or in the local government around here?

- Which level of government do you have the least faith and confidence in- the national government, the government of this state, or the local government around here?

These two questions allow us to categorize individuals by whether they trust the state or the federal government more. There are six possible orderings for trust (denoting state by $\mathrm{S}$, federal by $\mathrm{F}$, and local by $\mathrm{L}$ ), with $\succ$ representing a strict ordering: $S \succ F \succ L ; S \succ L \succ F ; L \succ S \succ F ; F \succ S \succ L ; F \succ L \succ S$; and $L \succ F \succ S$. Each of these is captured by the two questions above. For instance, if an individual answers that they have the most confidence in the state government and the least in the local government, then they must rank the federal government second (i.e., $S \succ F \succ L$ ). 
Recall that the estimation requires that we know the sign of $y^{*}$, a continuous latent variable that measures the difference in an individual's trust in the federal and state governments. The above orderings allow us to determine such a sign. When the state is trusted more than the federal government, this implies that $y^{*}>0$. This will be true for the first three orderings. The opposite will hold for the latter three. Thus, for each individual who responds to both of the above questions, we know whether $y^{*}<0$ or $y^{*}>0$. Using this definition, 62 percent of respondents trust the state government more than the federal government.

The results comport with the findings in the main analysis, though none of the campaign finance variables are statistically significant. ${ }^{30}$ (See Table A1 and A2 for summary statistics and results.) The substantive effect of public financing is negative. The presence of organizational limits increases an individual's likelihood of trusting state government, but this effect dissipates if individual limits are introduced alongside those organizational limits. This implies that trust declines when limits on individuals are instituted, reinforcing the finding that moving beyond basic campaign finance laws may in fact harm perceptions of government.

\footnotetext{
${ }^{30}$ Disclosure is omitted because it is present in all states, and other state-level institutions, such as the presence of the citizen initiative or term limits, are also omitted due to perfect collinearity.
} 


\section{Table A1. Summary Statistics for Trust Analysis}

\begin{tabular}{lr} 
Variable & Mean \\
\hline & .62 \\
Relative state trust & .15 \\
Contribution limits (organizations only) & .50 \\
Contribution limits (orgs. and ind.) & .23 \\
Public funding & .16 \\
Income=2 & .37 \\
Income=3 & .25 \\
Income=4 & .05 \\
Income=5 & .07 \\
Unemployed & .42 \\
High School & .27 \\
Some College & .27 \\
College & 47.64 \\
Age & 2578.90 \\
Age Squared & .23 \\
Nonwhite & .55 \\
Female & 2.93 \\
Partisan Strength & .53 \\
Democrat & .39 \\
Republican & .12 \\
Unified Dem. Govt. & .26 \\
Unified Rep. Govt. & .07 \\
Dem. x Unified Dem. & .13 \\
Dem. x Unified Rep. & .11 \\
Rep. x Unified Rep. & .04 \\
Rep. x Unified Dem. & .41 \\
Citizen Initiative & .73 \\
Gub. Term Limits & .38 \\
Leg. Term Limits & \\
Easy Registration & .05 \\
\hline
\end{tabular}

Summary statistics are from the 1996 National Election Study. Observations with missing data are excluded from the analysis. $\mathrm{N}=1316$. We present only the means because all variables (except for age, age squared, and partisan strength) are dichotomous. The standard deviations for the exceptions are as follows: age (17.59), age squared (1852.32), and partisan strength (.94). 


\section{Table A2. Trust in Government and Campaign Finance Laws}

\begin{tabular}{|c|c|c|}
\hline Variable & Coef. & z-stat \\
\hline Contribution limits (organizations only) & .169 & 1.03 \\
\hline Contribution limits (orgs. and ind.) & .077 & .62 \\
\hline Public funding & -.110 & 1.00 \\
\hline Income $=2$ & .317 & 2.18 \\
\hline Income $=3$ & .371 & 3.34 \\
\hline Income $=4$ & .314 & 2.50 \\
\hline Income $=5$ & .411 & 2.29 \\
\hline Unemployed & -.087 & .48 \\
\hline High School & -.168 & .71 \\
\hline Some College & -.227 & 1.12 \\
\hline College & -.303 & 1.36 \\
\hline Age & -.021 & 1.41 \\
\hline Age Squared & -.000 & 1.33 \\
\hline Nonwhite & .010 & .12 \\
\hline Female & -.013 & .14 \\
\hline Partisan Strength & -.121 & 2.61 \\
\hline Democrat & -.033 & .17 \\
\hline Republican & .746 & 4.38 \\
\hline Unified Dem. Govt. & -.284 & .65 \\
\hline Unified Rep. Govt. & .490 & 1.26 \\
\hline Dem. x Unified Dem. & .043 & .11 \\
\hline Dem. x Unified Rep. & -.685 & 1.83 \\
\hline Rep. x Unified Rep. & -.754 & 1.78 \\
\hline Rep. x Unified Dem. & -.011 & .02 \\
\hline Citizen Initiative & .027 & .25 \\
\hline Gub. Term Limits & -.024 & .27 \\
\hline Leg. Term Limits & .043 & .35 \\
\hline Easy Registration & .320 & 2.51 \\
\hline Constant & .769 & 1.71 \\
\hline
\end{tabular}

The probit specification includes region dummy variables with robust standard errors adjusted for clustering within state; absolute value of z-statistics are presented in the table. The dependent variable is coded 1 if individual trusts state government more than the federal government $($ mean $=.62) . \mathrm{N}=1316$. 